\title{
Study of Fractal Tree Antenna for Multiband Applications
}

\author{
S. Khobragade, S. Nalbalwar and A. Nandgaonkar \\ Dr. Babasaheb Ambedkar Technological University Lonere, Mangaon, Raigad, MH, India \\ \{svk2305@gmail.com, slnalbalwar@gmail.com, abnandgaonkar@yahoo.com\}
}

\begin{abstract}
Present day is witnessing a very rapid growth of wireless communication, for which antenna with very large bandwidth are in strong demand, so that various application are covered with fewer or preferably with single antenna. Fractals are profoundly intricate shapes that are easy to define. Fractals are space-filling contours, electrically large features can be efficiently packed into small areas. Fractal tree structures can be utilise to enhance the performance of the antenna such as widening the frequency band while reducing the size of an antenna. This paper summarize the different kind of tree design structure, development process, current research and application of the fractal tree antenna.
\end{abstract}

Keyword. Fractal Antenna, Fractal Tree, multi-band, ultra-wideband, miniaturization

\section{Introduction}

A fractal is rough fragmented geometric shape that can be split into parts, each of which is a reduced sized copy of the whole. The term fractal is coined by Benoit Mandelbrot in 1975 and was derived from the Latin word fractus, meaning broken or fractured [1].

Fractal provides the features such as fine structures at arbitrarily small scales, irregular to be easily describe in traditional Euclidean geometric language, self-similar, it has Hausdoff dimension which is greater than its topological dimension, it has simple and recursive definition. Fractal antenna response differs from traditional antenna design, in that it is capable of operating with good-to-excellent performance at many different frequencies.

Various fractal types other than fractal tree used in antenna are shown below Fig. 1

Cantor Set

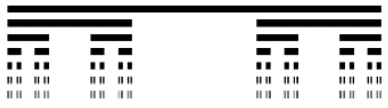

a: Cantor Set

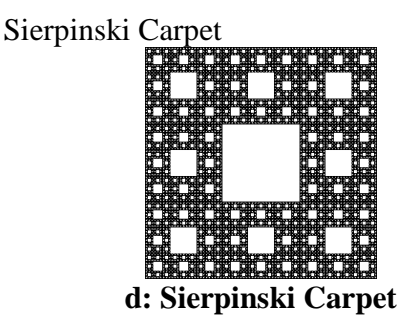

Koch Curve

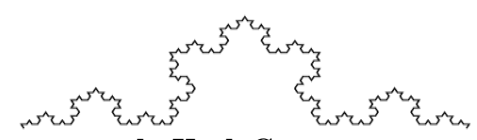

b: Koch Curve

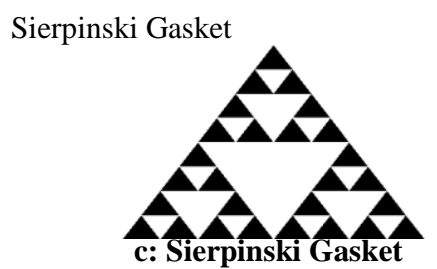

Koch Snowflake

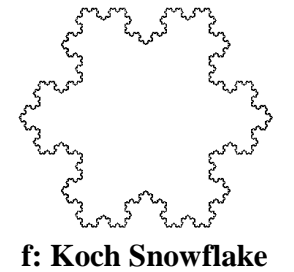

f: Koch Snowflake

Fig.1. Various Fractal other than fractal tree

B. Iyer, S. Nalbalwar and R. Pawade (Eds.)

ICCASP/ICMMD-2016. Advances in Intelligent Systems Research.

Vol. 137, Pp. 522-529.

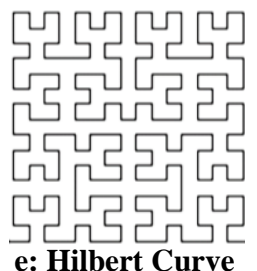

(C) 2017- The authors. Published by Atlantis Press

This is an open access article under the CC BY-NC license (http://creativecommons.org/licens)es/by-nc/4.) 


\section{Literature Review}

In 1973, Benoit Mandelbrot first proposed the idea of fractal geometry and fractal dimension. He define as fractal geometry is based on a form of symmetry that had previously been underused, namely invariance under contraction and dilation. He also says that fractal geometry is conveniently viewed as a language that as proven its value by its uses. Then, fractal theory was applied in various field of science and engineering [1]. In 1986, Kim and Jaggard [4] first time put forward that the theory of fractal could be implemented to the design of antenna and its array shown in Fig. 2. They combines the strength of both uniform and random arrays in the fractal array procedure, and concludes that uniform array possess relatively low side lobes and less sensitive to error compare to random array.
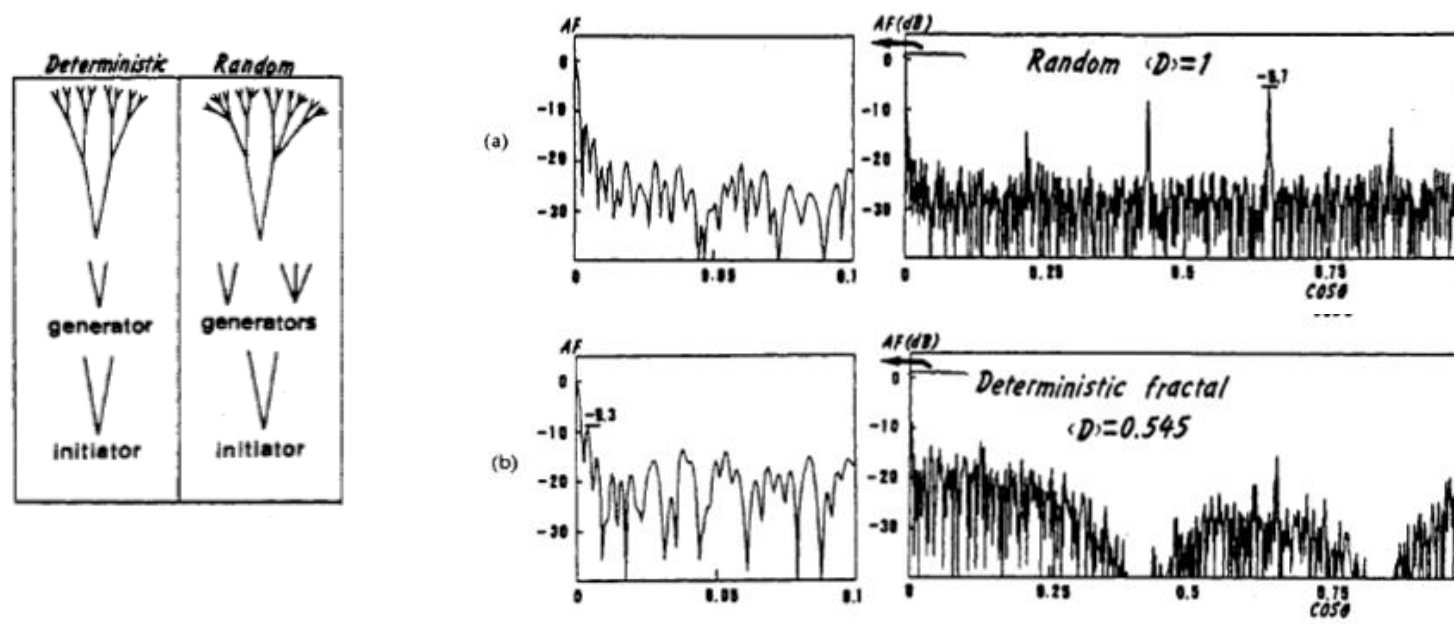

Fig. 2 Design and result proposed by Kim and Jaggard

In 1996, Puente et al., J. Claret, F. Saguks, J Romeu, M.Q. Lopez - salvans and R. Pous studied the multiband properties of fractal tree non deterministic antenna generated electrochemical deposition [5] shown in Fig. 3. They concludes that radiation properties of a random fractal aggregate generated by electrochemical deposition with monopole configuration shows rich distribution of scales into multifrequency behaviour. The distribution of the frequencies has been shown to be related to the distribution of length over the antenna.

(i)

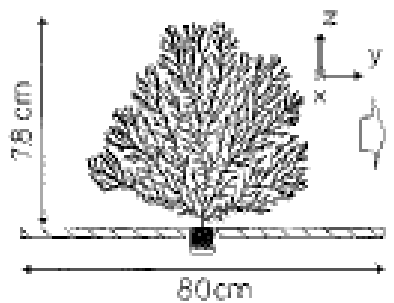

(ii)

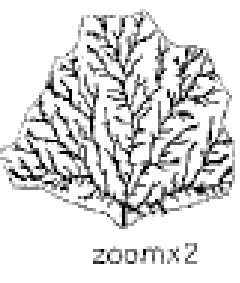

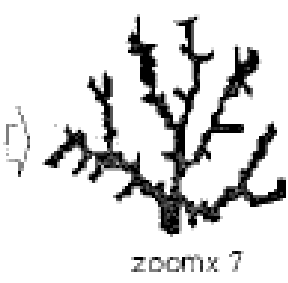

Fig. 3 Design with chemical deposition by Puente et al., J. Claret, F. Saguks, J Romeu, M.Q. Lopez - Salvans and R. Pous

In 1999, D. H. Werner Rubio Bretones and B R Long shown in Fig. 4, Present the work based on thin wire ternary fractal tree and conclude with self-similarity behaviour at specific bands [6]. In 2000, John P. Gianvittorio and Yahya Rahmat Samii [3] researched the miniaturization of dipole antenna that using fractal tree structure as end load. They compared the types of the fractal as a dipole also as a Koch dipole for 5 iteration shown in Fig. 5. Further in 2003, Douglas H. Werner and Suman Ganguly [7] proposed Tri-band ternary fractal tree antenna which suggest the reduction in the resonant frequency of a standard dipole can be achieved by end loading it with two dimensional or three dimensional tree like fractal structure shown in Fig. 6. This decreases 
in the resonant frequency shown asymptotically approach a limit as the number of iteration are increased. Since then, more and more researcher have been studying fractal tree antenna

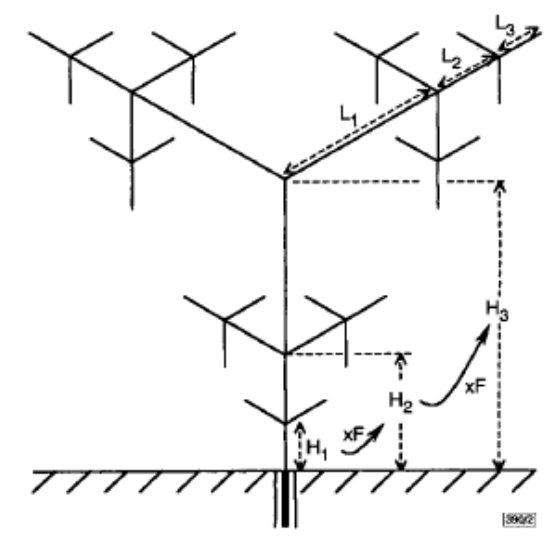

Fig. 4 Design by D. H. Werner Rubio Bretones and B R Long

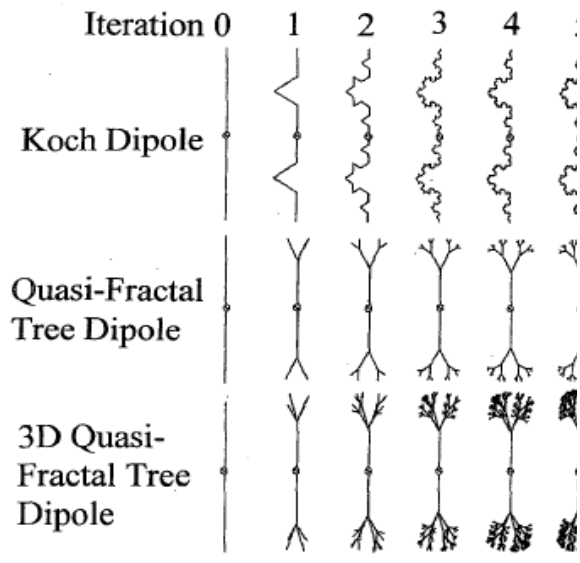

Fig. 5 Design proposed by John P. Gianvittorio and Yahya Rahmat Samii

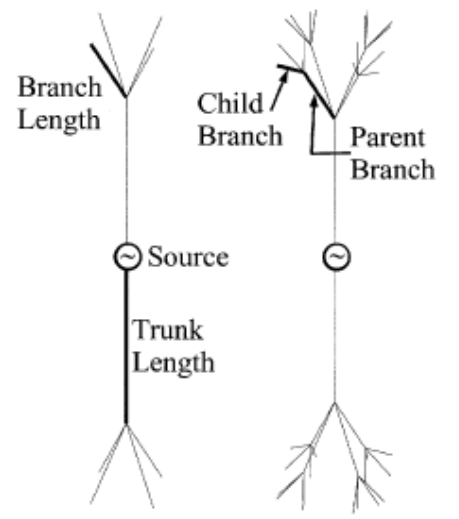

Stage 1

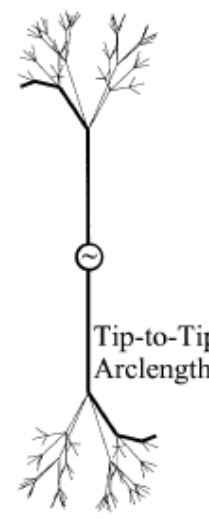

Stage 3

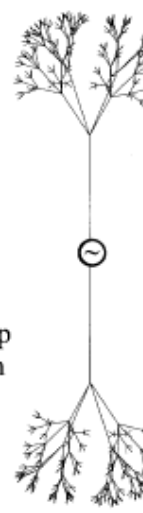

Stage 4

Fig. 6 Design proposed by Douglas H. Werner and Suman Ganguly

In 1996, Puente et al. demonstrated the multiband behaviour of the Sierpinski gasket antenna. They observe the multiband behaviour of the antenna which is dependent on the self-similarity property of the gasket. This may provide the new design of frequency independent and multiband antenna for researchers [5].

In 2004, Joshua Petko and D H Werner present the paper based on miniature configurable three dimensional fractal tree antenna in which they apply LC traps or RF switches strategically placed throughout the branches and /or along the trunk of the trees. A prime advantage of this is resonant frequency of the antenna can be spaced much closer than if they were applied to the tree trunks. They shows $57 \%$ in the size reduction for lowest band of operation [8]. In 2004, B. Ozbakis and A. Kustepeli proposed Novel design for fractal tree antenna application. They design fractal tree antenna using Fibonacci number sequence and non-uniform branch length ratio shown in Fig 7. Results shows 6 to 13\% shift in the resonant frequency for different iteration [9].

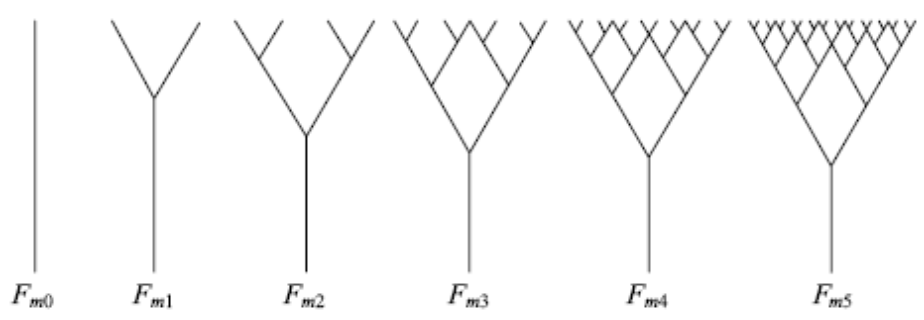

Fig. 7 Design with non-uniform branch length ratio 
In 2005, Mohammadi Bharmal and Dr. K J Vinoy proposed 5-iteration tree antenna shown in Fig. 8, the proposed antenna printed on $1.5 \mathrm{~mm}$ thick substrate $\left(\varepsilon_{r}=3.5\right)$ and conductor thickness of $5 \mu \mathrm{m}$. This antenna maintain $\mathrm{S}_{11}(10 \mathrm{~dB}$ Bandwidth) for frequency 6.2 to $6.8 \mathrm{GHz}, 7.5$ to $8.2 \mathrm{GHz}$ and 8.5 to $10 \mathrm{GHz}$. This is CPW feed UWB antenna explored to UWB Bandwidth, more variable to tune to the desired response like length of the stem, separation between ground and feed, iteration, scale factor, angle. It has CPW feed which simplifies the fabrication process [10].

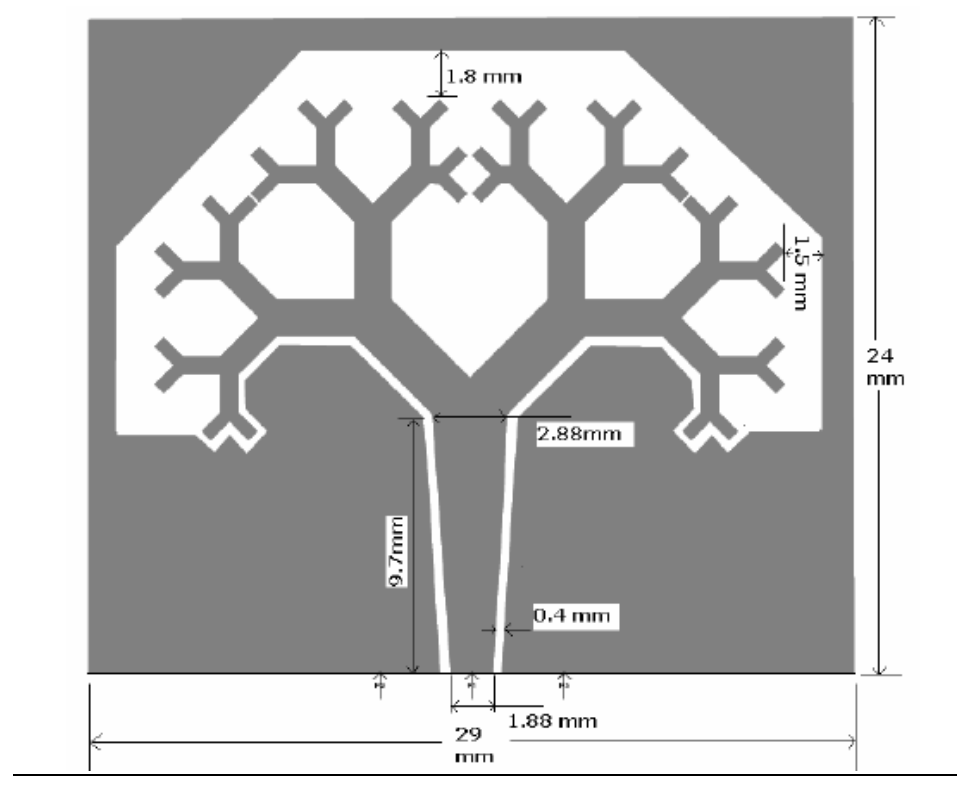

Fig. 8 Proposed 5-iteration tree antenna by Mohammadi Bharmal and Dr. K J Vinoy

In 2007 to 20015 many research scholar and scientist proposed different antenna based on different fractal tree antenna design shown in Fig. 9. In 2008 Yan su, Xiao Zheng Lai and Sheng Li Lai design fractal tree RFID tag antenna on papery substrate [11]. Hyo Won Song, He Soon An, Jung Nam Lee, Jong Kweon Park and Jin Suk Kim Design the Tree shaped UWB Antenna using fractal concept [12]. This antenna is good candidate for UWB application and show good impedance matching, radiation characteristics and gain characteristics for the range of $3.1-4.8 \mathrm{GHz}$ operating frequency. In 2009, Joshua S. Petko and Douglas Werner paper demonstrate Interleaved UWB Antenna array on optimized polyfractal tree structure. They used specially formulated genetic algorithm as well as multi objective optimization technique for the design [13]. One more design tried in the same year by Rui Guo, Xing Chen and Kama Huang for wideband Microstrip fractal Antenna based on fractal binary tree. They also used Genetic Algorithm with full wave EM simulation using FDTD on a cluster system [14]. Paper shows the wide impedance bandwidth up to $42.8 \%$ from 2.46 to $3.8 \mathrm{GHz}$ range.

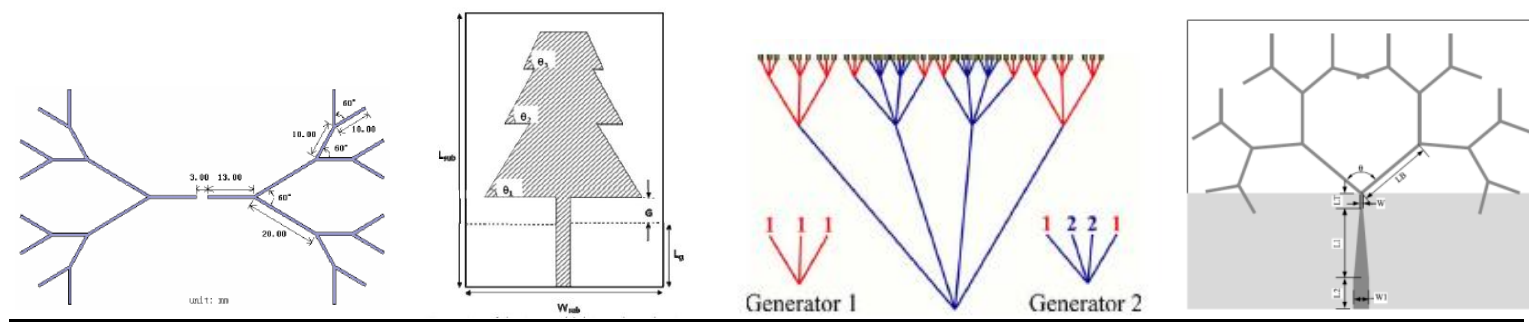

Fig. 9 Antenna proposed by different researches

In same year 2009, A Falahati, Naghshvarian Jahomi and R. M. Edwards design dual band notch CPW Ground fed UWB Antenna based on fractal binary tree [15]. This is miniaturize size delivers a good radiation patterns with monopolar characteristics. 
The gain of the antenna is suppressed very well in WLAN bands. 2010, A Aggarwal and M. V. Kartikeyan design Pythagoras tree fractal patch antenna for multifrequency and UWB operations. It was design for WLAN / WiMAX (2.4 GHz) and WiMAX (3.5GHz) [16]. This antenna shows the dual band performance and achieve more than 20\% impedance bandwidth achieved at both the frequency bands. In 2011, Javed Pourahmadazar, Changiz Ghobadi and Javad Nourinia work on the same kind of Pythagoras tree fractal patch antenna with slight modification. This antenna shows the result in UWB band and good impedance matching with the improvement in the impedance bandwidth too [17]. In 2012, Sanjay Khobragade and Anitha V R present the papers on two design based on fractal tree antenna. One design based on the tree with the help of rectangular and triangular patches connected with the wire antenna and other with simple design with five iteration. First antenna design for $2.4 \mathrm{GHz}$ and $3.6 \mathrm{GHz}$ frequency and shows the $\mathrm{S}_{11}$ bandwidth of $9.5 \%$ and $31.5 \%$ respectively [18] [20]. Second design presented by Sanjay Khobragade and Anitha V R present antenna for the range of 2.1 to $2.8 \mathrm{GHz}$ resonant frequency. It is good candidate of multiband frequency application which have the application in Bluetooth, Wireless LAN etc. [19] [20]. All antennas are shown in Fig. 10.

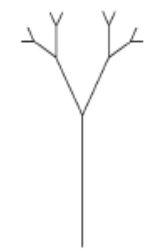

Branch angle $2 \theta=60^{\circ}$

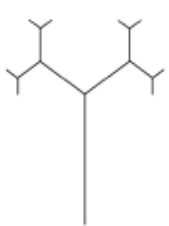

$120^{\circ}$

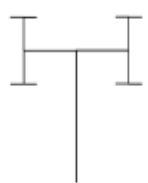

$180^{\circ}$

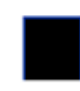

Iteration 0

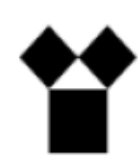

Iteration 1

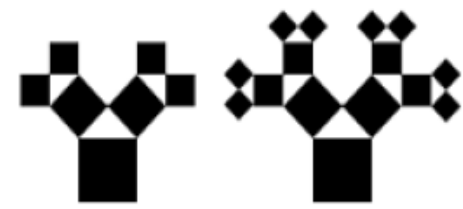

Iteration 2

Iteration 3

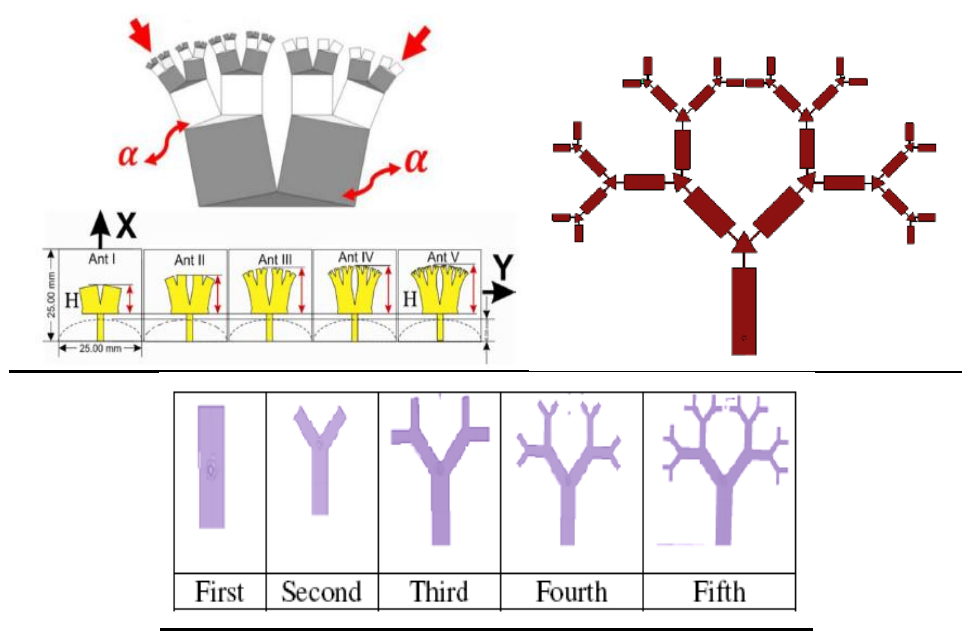

Fig. 10 Antenna proposed by different researches

In 2011 first time Huseyin Altun, Erdal Korkmaz and Bahattin Turetken present the paper based on fractal tree reconfigurable antenna for multiband application. They uses 8 PIN diode 4 at the corners of part 1 and remaining four at the joint of parent and child branches [21]. They got multiband output for the different possible ON- OFF condition of the PIN diode switches shown in Fig. 11. The frequency range varied from 1.51 to $8.6 \mathrm{GHz}$. In 2013 Anitha V R and Malli Yuva Sindhu [22] tried the same in the design which is the extension of design presented by Sanjay Khobragade and Anitha V R [18], [19], [20] based on rectangular and triangular patches where wire replace by switches. This antenna covers the service band such as WLAN $2.4-2.42 \mathrm{GHz}$ and WiMAX $3.4-3.8 \mathrm{GHz}$ resonant frequency also shows the other band 2.4 to $3.8 \mathrm{GHz}$. In 2014 Sumit Rakibe, Sonali Sahu and Sanjay Khobragade present the paper on reconfigurable antenna for application such as WiMAX (2.4-2.483) GHz WiMAX (3.4 - 3.6) GHz and WLAN (5.15-5.825) GHz and some other frequencies between 2-10 GHz. 6 PIN diodes used for the design of the antenna and tested for the different possible ONOFF condition of the switches shown in Fig. 12 [23]. 


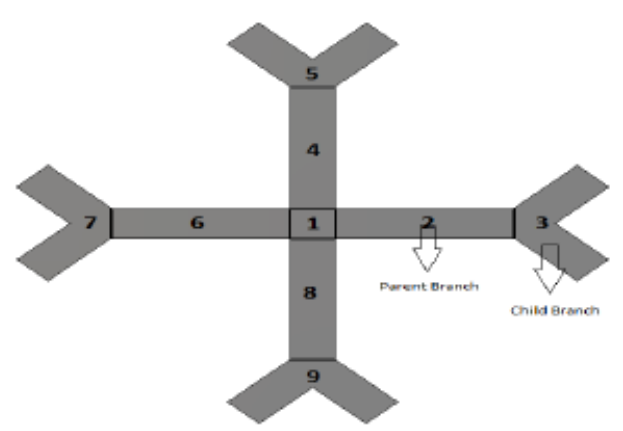

Fig. 11 Reconfigurable Antenna proposed by Huseyin Altun, Erdal Korkmaz and Bahattin Turetken

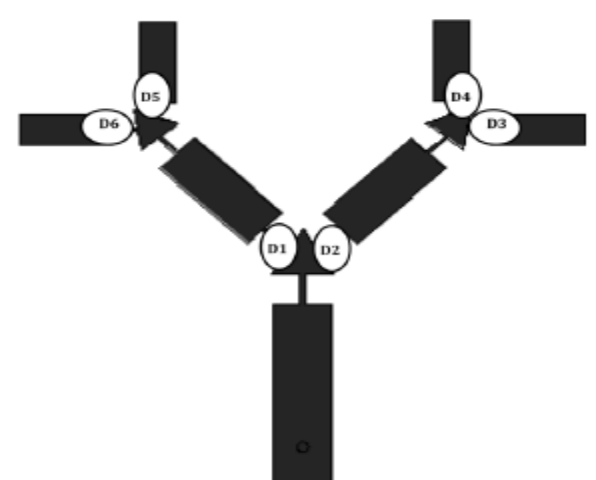

Fig. 12 Reconfigurable Antenna proposed by Sumit Rakibe, Sonali Sahu and Sanjay Khobragade

\section{Comparative study of the Reference Antennas}

Following table shows the comparative studies of the reference antenna. Reference number 2 to 23 antenna are used for the comparison.

Table I. Comparative study of the reference Antennas

\begin{tabular}{|c|c|c|c|c|c|c|c|}
\hline Ref & $\begin{array}{l}\text { Feeding } \\
\text { Technique }\end{array}$ & $\begin{array}{l}\text { Resonant } \\
\text { Frequency }\end{array}$ & $\begin{array}{l}\text { Branch } \\
\text { Angle }\end{array}$ & $\begin{array}{l}\text { (Return } \\
\text { Loss) }\end{array}$ & $\begin{array}{ll}\text { Mode } & \text { of } \\
\text { Operation } & \end{array}$ & $\mathbf{B} / \mathbf{W}$ & Remark \\
\hline 2 & $\begin{array}{l}\text { Coaxial, } \\
\text { Monopole }\end{array}$ & $\mathrm{f}_{1}, \mathrm{f}_{2}, \mathrm{f}_{3}, \mathrm{f}_{4}$ & $30^{\circ}$ to $180^{\circ}$ & NA & Multiband & NA & $\begin{array}{l}\text { Comparison of resonant } \\
\text { frequency ratio }\end{array}$ \\
\hline 3 & Coaxial & $1-1.9 \mathrm{Ghz}$ & $60^{\circ}$ & NA & Single band & NA & $\begin{array}{l}\text { Calculate Resonant Freq. and } \\
\text { quality factor }\end{array}$ \\
\hline 4 & Coaxial & NA & NA & NA & Multiband & NA & $\begin{array}{l}\text { Discuss deterministic and } \\
\text { random array }\end{array}$ \\
\hline 5 & Monopole & $0.9-8 \mathrm{GHz}$ & NA & NA & Multiband & NA & $\begin{array}{l}\text { Radiation properties has been } \\
\text { tested }\end{array}$ \\
\hline 6 & Monopole & $0.1-2 \mathrm{GHz}$ & $120^{\circ}$ & & Multiband & & $\begin{array}{l}\text { Impedance behaviour is } \\
\text { studied }\end{array}$ \\
\hline 7 & Coaxial & $0.1-2 \mathrm{GHz}$ & $120^{\circ}$ & NA & Multiband & NA & $\begin{array}{l}\text { Impedance behaviour is } \\
\text { studied }\end{array}$ \\
\hline 8 & Monopole & $0.8-6.4 \mathrm{GHz}$ & $0-315^{0}$ & $\begin{array}{l}-32 \mathrm{~dB} \\
\max .\end{array}$ & $\begin{array}{l}\text { Multiband / } \\
\text { Reconfigurable }\end{array}$ & $70 \%$ & $\begin{array}{l}\text { Effective in significant size } \\
\text { reduction }(57 \%)\end{array}$ \\
\hline 9 & Coaxial & $1.1-1.9 \mathrm{GHz}$ & $60^{\circ}$ & NA & Multiband & NA & $\begin{array}{l}\text { Design the antenna with } \\
\text { Fibonacci seq. }\end{array}$ \\
\hline 10 & CPW & $6.2-10 \mathrm{GHz}$ & Variable & $-28 \mathrm{~dB}$ & Multiband & UWB & $\begin{array}{l}\text { Matched to desired } \\
\text { Impedance }\end{array}$ \\
\hline 11 & Coaxial & $0.6-1.0 \mathrm{GHz}$ & $0-180^{\circ}$ & $\begin{array}{c}-24.2 \mathrm{~dB} \\
\max \\
\end{array}$ & Multiband & & $\begin{array}{l}\text { Shows the size reduction of } \\
\text { RFID tag ant. Effectively }\end{array}$ \\
\hline 12 & Monopole & $2.7-6.4 \mathrm{GHz}$ & $0-90^{0}$ & $\begin{array}{c}-48 \mathrm{~dB} \\
\max \end{array}$ & Multiband & $81.3 \%$ & $\begin{array}{l}\text { Proposed antenna id good } \\
\text { candidate of UWB apps. }\end{array}$ \\
\hline 13 & Coaxial & $10 f_{0}$ & $\begin{array}{l}60^{0} \text { from } \\
\text { Broadside }\end{array}$ & NA & Multiband & $20: 1$ & $\begin{array}{l}\text { Presented Interleaving } \\
\text { antenna array using GA }\end{array}$ \\
\hline 14 & Monopole & $2.4-3.8 \mathrm{GHz}$ & $102.4^{0}$ & $-42.8 \mathrm{~dB}$ & Multiband & $40.8 \%$ & $\begin{array}{l}\text { Antenna is optimise using } \\
\text { GA and FDTD }\end{array}$ \\
\hline 15 & CPW & $3.5-10.2 \mathrm{GHz}$ & $60^{0}-180^{0}$ & NA & Multiband & UWB & $\begin{array}{l}\text { Dual band notch antenna } \\
\text { design using single slot }\end{array}$ \\
\hline 16 & $\mathrm{CPW}$ & $2.4-3.5 \mathrm{GHz}$ & $45^{0}$ & $\begin{array}{c}-38 \mathrm{~dB} \\
\max \end{array}$ & Multiband & $33.5 \%$ & $\begin{array}{l}\text { Pythagoras Tree Antenna, } \\
20 \% \text { BW enhancement }\end{array}$ \\
\hline 17 & Monopole & $3.8-8.26 \mathrm{GHz}$ & $45^{0}$ & $\begin{array}{l}-46 \mathrm{~dB} \\
\mathrm{Max}\end{array}$ & Multiband & $123 \%$ & $\begin{array}{l}\text { Good Impedance match and } \\
\text { improvement in BW }\end{array}$ \\
\hline 18 & $\begin{array}{l}\text { Proximity } \\
\text { Couple }\end{array}$ & $2.4-3.6 \mathrm{GHz}$ & $60^{\circ}$ & $\begin{array}{c}-44 \mathrm{~dB} \\
\max \end{array}$ & Multiband & $31.5 \%$ & $\begin{array}{l}\text { Shows the adequate BW and } \\
\text { Gain }\end{array}$ \\
\hline 19 & Coaxial & $2.3-3.6 \mathrm{GHz}$ & $60^{\circ}$ & $-17 \mathrm{~dB}$ & Multiband & $87.8 \%$ & $\begin{array}{l}\text { The proposed antenna show } \\
\text { the good BW }\end{array}$ \\
\hline
\end{tabular}




\begin{tabular}{|l|l|l|c|c|l|c|l|}
\hline 20 & $\begin{array}{l}\text { Coaxial / } \\
\text { Microstrip }\end{array}$ & $2 \mathrm{GHz}$ & $60^{0}$ & $\begin{array}{c}-37 \mathrm{~dB} \\
\max \end{array}$ & Multiband & $32 \%$ & $\begin{array}{l}\text { comparison between coaxial } \\
\text { v M/strip line feed }\end{array}$ \\
\hline 21 & Coaxial & $2.9-8.6 \mathrm{GHz}$ & $0-90^{0}$ & & $\begin{array}{l}\text { Multiband } \\
\text { Reconfigurable }\end{array}$ & NA & $\begin{array}{l}\text { Reconfigurable structure is } \\
\text { discuss with PIN diode }\end{array}$ \\
\hline 22 & Coaxial & $2.4-3.8 \mathrm{GHz}$ & $60^{0}$ & $\begin{array}{c}-18 \mathrm{~dB} \\
\max \end{array}$ & $\begin{array}{l}\text { Multiband } \\
\text { Reconfigurable }\end{array}$ & $60 \%$ & $\begin{array}{l}\text { Reconfigurable structure is } \\
\text { discuss with PIN diode }\end{array}$ \\
\hline 23 & Coaxial & $2-10 \mathrm{GHz}$ & $90^{0}, 45^{0}$ & $-27 \mathrm{~dB}$ & $\begin{array}{l}\text { Multiband } \\
\text { Reconfigurable }\end{array}$ & NA & $\begin{array}{l}\text { Reconfigurable structure is } \\
\text { discuss with PIN diode }\end{array}$ \\
\hline
\end{tabular}

\section{Conclusion}

This paper introduces the review of the paper based on fractal tree antennas which start from the definition of the fractal by Mandelbrot. Fractal has space filling and self-similarity properties so compact fractal may operate at RFID, Mobile phones, WI-FI, Bluetooth, WIMAX and so many applications at the same time. Out of the 23 reference antennas 19 antennas are purely based on the multiband behaviour. Remaining four antennas shows the multiband as well as reconfigurable property. Many antennas show the resonance frequency bandwidth and application in UWB range. Some antennas like reference number [13] and [14] present the paper with genetic algorithm. Reconfigurable antenna presents the technique of adding the PIN diode or RF/ MEMS switches in fractal antenna geometries. By making the switches ON-OFF the resonant frequency can be shifted accordingly. Some Antennas are Coaxial, monopole, CPW and one antenna is proximity coupled antenna, so there is scope for other types of feeding techniques to use in the fractal tree antenna design. There is scope to use this antenna for the bandwidth and gain enhancement too since none of the antenna focus on this area. There are two papers discuss with the chemical deposition techniques. Its shows the multiband, wideband behaviour with good gain and radiation characteristics. So researchers can try with many ways in the chemical deposition methods to see the different parameters behaviour. Researchers can also work on multilayer fractal structure with different dielectric substrate or metamaterials. It can be summarised that increasing the fractal tree dimension leads to fractal miniaturization. Applications are increasingly widespread in the field of science and engineering.

\section{References}

[1] Mandelbrot B B: Fractal Geometry: What is it? And what does it do? , Proceeding of R. Soc. London. A423, 3-16(1989)

[2] Vinoy K J, Jose K. and V “K Vardhan: Fractal Dimension and Frequency of Fractal Shaped Antennas, Antenna and Propagation Society International Symposium, 2003 IEEE, Volume 4, Year 2003

[3] John P. Gianvittorio and Yahya Rahmat Samii: Fractal Antennas: A Novel Antenna Miniaturization Technique, and Applications, IEEE Antenna and Propagation Magazine, vol. 44, No. 1, February 2002.

[4] Y Kim and D L Jaggard: The Fractal Random Array, Proceedings of the IEEE Volume 74, No.9, September 1986

[5] Puente C, Claret J, Sagues F, Romeu J, Lopez Salvans M Q and Pous R: Multiband Properties of fractal tree antenna generated by electrochemical Deposition, Electronics Letters, Vol.32, no.25, pp. 2298-2299, December 1996

[6] Werner D H, Rubio Bretones A and Long B R: Radiation Characteristics of thin-wire ternary fractal trees, Electronics Letters 15 April 1999, Volume 35.

[7] Douglas H Werner and Suman Ganguly: Overview of Fractal Antenna Engineering Research, IEEE Antenna and Propagation Magazine, Volume 45, No. I, February 2003

[8] Joshua S Petko and Douglas H Werner: Miniature reconfigurable tree- dimensional fractal Tree Antennas, IEEE Transaction on Antennas and Propagation, Vol. 52, No. 8, August 2004

[9] Ozbakis B, Kustepeli A: Two Novel Design for fractal Tree Antenna Applications, URSI EMTS 2004, pp 245-247

[10] Mohammadi Bharmal and Dr. Vinoy K J, "Design of fractal UWB Antenna" http://www.ece.iisc.ernet.in/ kjvinoy/adspdf/Mohammadi.pdf

[11] Yan Su, Xiao Zheng Lai and Sheng li Lai: Research on Fractal Tree RFID tag antenna on papery Substrate, in proceeding of $4^{\text {th }}$ International Conference on wireless Communication, Networking and Mobile Computing, pp. 1-3, Dalian, October 2008 
[12] Hyo-Won Song, Hee-Soo An, et al: Design of the Tree shaped UWB antenna using Fractal Concept, Microwave Conference, 2007, KJMW 2007, Korea-Japan, pp. 73-76, November 2007.

[13]Joshua S Petko and Douglas H Werner: Interleaved Ultra wideband Arrays based on Optimized Polyfractal Tree Structures, IEEE Transaction on Antenna and Propagation, Vol. 57, No. 9, September 2009.

[14] Rui Guo, Xing Chen and Kama Huang: A Novel wideband Microstrip Antenna based on the fractal binary Tree, Electromagnetics, Vol. 29, no. 4, pp.283-290. May - 2009

[15] Falahati A, Naghshvarian-Jahromi M, Edwards R M: Dual Band Notch CPW - Ground - Fed UWB Antenna by Fractal Binary Tree slot, 2009 IEEE Fifth International Conference on Wireless and Mobile Communications, pp 385-390

[16] Aggarwal A and Kartikeyan M V: Pythagoras Tree: A Fractal patch Antenna for Multiband and ultra wide band width operations, Progress in Electromagnetics Research C, Vol. 16, pp. 25-35, 2010

[17] Javed Pourahmadazar, C. Ghobadi, J Nourinia and H Shirzad: Novel Modified Pythagorean Tree Fractal Monopole Antenna for UEB Application, IEEE Antennas Wireless Propagation Letters, Vol. 10, pp. 484-487, 2011

[18] Sanjay Khobragade and Anitha V R: Innovative Design of Tree Shaped Fractal Antenna Using Rectangular and Triangular Patches for 2.4 GHz. IJECET, Vol. 3, Issue 1, January-June 2012, pp. 188193.

[19] Sanjay Khobragade and Anitha V R: Design and Simulation of Fractal Tree Antenna for Wireless Application. IJECET, Vol. 3, Issue 1, January-June 2012, pp. 178-187.

[20] Sanjay Khobragade, Anitha V R, Jankiraje Bhosale: Fractal Tree Antenna for WLAN Application, International Conference on Electronics Computer Technology (ICECT 2011) April 8 - 10, 2011 kanyakumari, India. Sponsored and published in IEEE Explorer.

[21] Huseyin Altun, Erdal Korkmaz, and Bahattin Turetken: Reconfigurable Tree Antenna for Multiband Applications, General Assembly and Scientific Symposium, 2011 XXXth URSI, pp.1-4, Istanbul, August 2011

[22] Dr. Anitha V R and Malli Yuva Sindhu: Simulation of a novel Design Fractal Tree Antenna for Multiband Application with Re-Configurability, in proceedings of the 2013 IEEE-APS Topical Conference on Antenna and Propagation in wireless Communications, pp. 148-149, Torino, September 2013.

[23] Sumit Rakibe, Sonali Sahu and Sanjay Khobragade: Fractal Antenna for multi -Frequency application using PIN diode, Springer (J Computational Electron DOI10.1007 / s10825 - 014 - 0640 - 6)

[24] Vinoy K J, Fractal shaped antenna elements for wide and multiband wireless applications, Thesis, Pennsylvania, August 2002.

[25] Wei Cao and Lanling Zeng: Natural Tree Modelling based on Fractal, 2009 sixth international conference on fuzzy system and knowledge discovery. (IEEE Computer Society)

[26] Chunhua Wang, Kejian Yang, Dong Han: New Modelling Methods for Trees, 2008 International conference on Advance Computer Theory and Engineering, (IEEE Computer Society)

[27] Kulbir singh, Vinit Grewal and Rajiv Saxena: Fractal Antennas: A Novel Miniaturization Technique for wireless communications, International Journal of Recent Trends in Engineering, Vol. 2, No. 5, November 2009

[28] Joshua S. Petko, D. H. Werner: Dense 3-D Fractal Tree structures as miniatures end-loaded dipole Antenna, IEEE 2002, pp 94-97

[29] Hongming Zang, Xiaoying Zhao, Xiong Xu, Gonglei Zhang, Jingjing Lu: A Review of fractal Tree Antennas, International Conference on future computer and communication Engineering (ICFCCE 2014), pp15-18

[30] Sujeet Kumar Yadav, Kirti Vyas, Sudarshan Kumar: A Pythagoras Tree Shaped Fractal Antenna for Multiband Applications, International Journal of Emerging Technology and Advanced Engineering, Vol. 3, Issue 12, December 2013, pp572-576

[31]Guo Liu, Liang Xu and Zhensen Wu: Dual band Microstrip RFID Antennas with Tree like Fractal Structure, IEEE Antennas and Wireless Propagation Letters Vol. 12, 2013, pp 976-978

[32] H. Kimouchfe, M. Bitchikh, B. Atrouz, "Novel design of a Fractal Monopole Antenna for Wireless Communication, IEEE 2008 